Estudios sobre el Mensaje Periodístico ISSN-e: 1988-2696

http://dx.doi.org/10.5209/ESMP.55612

\title{
Del retrato de la Dama de Hierro a la fotografía de Mutti Angela: la representación icónica de la canciller alemana Angela Merkel
}

\author{
Raquel Quevedo Redondo; Miriam Suárez-Romero²
}

Recibido: 11 de marzo de 2016 / Aceptado: 24 de octubre de 2016

Resumen. La investigación condensada en estas páginas se basa en el poder de denotación de la fotografía y en la utilidad del análisis de contenido para esclarecer cuál es la representación de Angela Merkel acuñada en 2015 por cinco diarios españoles de referencia. Concretamente, prima la intención de comprobar si los rasgos característicos de una metáfora extemporánea como es el rol de Dama de Hierro permean la imagen que los diarios generalistas proyectan sobre la canciller alemana, y si las actitudes que se le atribuyen coexisten con otras propias de la tradicional interpretación de la naturaleza femínea. Al término del artículo se propone el empleo de una tabla de identificación que permite reconocer en una instantánea si ésta responde a la idiosincrasia de los dos roles más comunes vinculados a Merkel.

Palabras clave: Angela Merkel; prensa española; análisis fotográfico; género.

[en] From Iron Lady's portrait to Mutti Angela's photography: the iconic treatment of German Chancellor Angela Merkel

\begin{abstract}
The research presented in these pages rests on the photography's denotation power, as well as on the usefulness of the content analysis technique in order to clarify which is Angela Merkel's representation. So as to, five Spanish newspapers are analysed during 2015. Specifically, the prevalent intention is to check if the characteristic features of an extemporaneous metaphor - as it is the role of Iron Lady - pervade the image projected by the mainstream press onto the German Chancellor. In addition, it is investigated whether the attributed attitudes coexist with traditional female interpretation features. Moreover, at the end of the article, the use of an identification table is proposed. It would help to recognize if a picture responds to the idiosyncrasies of the two most common roles linked to Merkel.
\end{abstract}

Keywords: Angela Merkel; Spanish press; photographic analysis; gender.

Sumario. 1. Introducción. 2. Contextualización del objeto de estudio e hipótesis. 3. Diseño metodológico. 4. Resultados. 5. Conclusiones. 6. Referencias bibliográficas.

Cómo citar: Quevedo Redondo, Raquel y Suárez Romero, Miriam (2017): “ Del retrato de la Dama de Hierro a la fotografía de Mutti Angela: la representación icónica de la canciller alemana Angela Merkel", en Estudios sobre el Mensaje Periodístico 23 (1), 535-551.

\footnotetext{
1 Universidad de Valladolid.

E-mail: raquel.quevedo.redondo@uva.es

2 Universidad de Sevilla.

E-mail: mirsuarom@gmail.com
} 


\section{Introducción}

La segunda década del siglo XXI ha traído consigo un renovado interés científico por las formas de representación mediática del universo femenino, que desde los años 80 , y de acuerdo con los planteamientos expuestos en ese periodo por autores como Perinat y Marrades (1980), Sapiro (1981), Lefebvre (1983), Fagoaga y Secanella (1984) o Domínguez (1988), puede considerarse un objeto de estudio instituido.

El empleo del verbo "renovar" en el primer párrafo introductorio no es casual, sino que en este caso responde a una afán por evidenciar la creciente popularidad de las investigaciones con perspectiva de género, al tiempo que a través del recurso lingüístico del lexema compartido se vehicula la contextualización de la presente propuesta en el escenario donde experimenta su auge otro concepto de plena actualidad: la nueva política.

Nuevo. Novedoso. Novedad... Son palabras que habitualmente evocan un hallazgo de lo desconocido, aunque con frecuencia su uso más bien alude a una revisión y reformulación de las propias bases u orígenes. No en vano, eso ocurre en el ámbito gubernamental, sobre el cual hace ya más de cien años que José Ortega y Gasset explicitó su idea de divergencia entre lo antiguo y lo reciente. "La nueva política es menester que comience a diferenciarse de la vieja política en no ser para ella lo más importante, en ser para ella casi lo menos importante la captación del gobierno, y ser, en cambio, lo único importante el aumento y fomento de la vitalidad", aseguró el filósofo durante una conferencia en el teatro de la Comedia de Madrid en 1914.

Hoy en día, cuando se habla de un modelo alternativo y rupturista con la interpretación clásica del poder, esa búsqueda de lo vital a la que se refería Ortega y con la que él subrayaba la importancia de crear mayores "lazos de sociabilidad" entre representantes y representados (López Aranguren, 1997:21) redirige, de manera prácticamente instintiva, al proceso humanizador que radica en los confines de la naturaleza femenina, apostando por conectar al individuo con la sociedad, en contraste con la visión etnocéntrica anquilosada en el yo masculino. Como consecuencia, la arena pública, históricamente reservada al hombre, parece abocada a experimentar una feminización que, además de enlazar con la progresiva incorporación de las lideresas al ejercicio gubernativo, impregne de los valores tradicionalmente asociados a la mujer el modo convencional de ejercer y comunicar lo político. Ante esta realidad, numerosos investigadores se detienen a reflexionar y a responder, en primer lugar, a una concisa pregunta: ¿varían los tipos de liderazgo y su proyección en función del género? (Rosener, 1990; Bass et al., 1996; Eagly y Johannesen-Schmidt, 2001; Delgado, 2004; Ramos, 2005; García-Retamero y López-Zafra, 2006).

Para el común de los estudiosos, las diferencias existen. Dentro del espacio de poder, la percepción del varón ha derivado con el paso del tiempo en la formación de roles que enfatizan la firmeza, la competitividad, el dominio y la practicidad (Holmes, 2006; Priola y Bannan, 2009), mientras sus homólogas encarnan modelos transformacionales centrados en la interacción humana, la empatía y la trascendencia de las emociones (Huddy y Terkildsen, 1993; Cuadrado, 2003; Burrel, 2004). El resultado es que el estilo femíneo enraizado en los hábitos del trabajo en equipo ha generado oportunas sinergias para romper con la jerarquía piramidal, pero también ha propiciado el perfecto caldo de cultivo para la prolongación de una serie de tópicos forjados en torno al cumplimiento de los arcaicos estereotipos. De esta manera, a un mismo nivel de cargo y responsabilidad, aún se interpreta que ellas desempeñan 
el papel de gobernantes-cuidadoras de la ciudadanía, y ellos, el de gobernantes-proveedores del Estado (Fraser, 1997).

Desde la perspectiva de los mass media, ministras y alcaldesas son féminas antes que profesionales políticas (Norris, 1997; Falk, 2008; Fernández, 2010), y en relación con esta línea de pensamiento, sujetos en los que no se prevé el empleo de un lenguaje abiertamente asertivo, ya sea en el plano verbal o en el físico (Trent y Friedenberg, 1995:135-136). Así, cuando quien ostenta el bastón de mando enfrenta con su apariencia y comportamiento el patrón implícitamente establecido, nuevos marcos son acuñados por los medios para evidenciar la conjunción entre rasgos de personalidad, formas de comunicación y competencias temáticas que se entienden masculinizadas y rompen, por tanto, con el cliché de la mujer dócil y deferente.

En consonancia con Leonie Huddy y Nayda Terkilsen (1993a:120), de las conductas disconformes con el arquetipo acostumbrado se infiere una suerte de infracción de las reglas que, lejos de afluir en la transformación de los modelos conservadores, refuerzan su coexistencia con otros basados en lo que de singular tiene adoptar cualidades del sexo opuesto. Dicho con otras palabras, se observa un rechazo del "estereotipo académico de la mujer política" sobre el que disertaba López-Hermida en un estudio de 2011, y frente a la demostración de afectividad, cortesía, compasión y apacibilidad que se presupone inherente al papel de las representantes públicas, los agentes mediáticos impelen nombrar las particularidades de lo diferente bajo una misma metáfora acuñada en el pasado, inexorablemente unida a la concepción de la vieja política y que, como se explicitaba al comienzo de este epígrafe, precisa una revisión de sus orígenes. Los orígenes de las Damas de Hierro.

\section{Contextualización del objeto de estudio e hipótesis}

Cordelia Fine (2011), Juana Gallego (2013) y Karen Ross (2013) son algunas de las académicas que abordan en sus estudios la extrapolación y las connotaciones del famoso apodo que el periodista Yuri Gavrílov atribuyó en los años 70 a la ex primera ministra británica Margaret Thatcher.

El calificativo surgió de una comparativa que hizo Gavrílov entre el carácter de la gobernante inglesa y el del alemán Otto Von Bismarck, quien pasó a la historia como "Canciller de Hierro" por la inflexibilidad que distinguía su gestión. Muy pronto, el diario Sunday Times se hizo eco del paralelismo y la ocurrencia fue aceptada por la propia Thatcher, quien aprobó el uso de la expresión "The Iron Lady" durante la campaña electoral de 1979. A partir de aquel momento, cada vez que una mujer ocupaba un cargo político y daba muestras de tener una personalidad fuerte o una actitud poco complaciente, los medios de comunicación optaban por transformar la seda en metal (Gallego, 2013:61).

Hillary Clinton, Condoleezza Rice o la vicepresidenta del Consejo de Estado de la República Popular China, Wu Yi, integran sólo un pequeño segmento del nutrido grupo de poderosas que ha recibido el apelativo arraigado al thatcherismo. A ninguna de ellas, sin embargo, se le ha otorgado con tanta frecuencia e intensidad como a Angela Merkel.

En atención al panorama que delinean los medios, la canciller de Alemania ha pasado a ser considerada nueva Dama de Hierro y máximo exponente de las profesionales competentes, pero frías; correctas, pero distantes; resolutivas, pero 
esencialmente cerebrales (Fine, 2011), y, en definitiva, contrarias a los valores feminizantes que pregona la nueva política y que contradicen uno de los cuatro "roles trampa" identificados en 1977 por la profesora Rosabeth Kanter.

En su obra, Kanter no sólo habla de doncellas de acero, pues acota además el papel de la mujer seductora, la niña (el ser dócil e inocente) y, por supuesto, la progenitora. Esta última equiparación, la más extendida por su encumbramiento como principal distinción biológica entre los sexos, se aplica también a la lideresa alemana, quien a pesar de no tener hijos es frecuentemente presentada en prensa y televisión como "Mutti Angela" —Mamá Ángela-, en referencia a su condición femenina $\mathrm{y}$, con especial asiduidad en los últimos meses, por sus medidas de apoyo a los refugiados. Ambas proyecciones, la de madre protectora y la de férrea gobernante, comparten presencia en el plano mediático, aunque la segunda de ellas acapara el principal protagonismo y es la que permite comprobar como su utilización corre pareja al empleo de un estilo promotor de imágenes negativas para el receptor.

Teniendo en cuenta la influencia de los medios en la formación de la opinión pública, la presente propuesta asume la importancia de sobrepasar los límites del análisis del discurso que emplean reporteros y columnistas para referirse a Merkel y escrutar, a partir de una meticulosa tarea analítica, el grado de coherencia entre lo que de ella se dice y lo que de ella se muestra. Desde esta idea, se toma como referencia la obra de Pericot (2002) y se afronta el retrato como superación de la simple representación gráfica de un objeto real que, lejos de ser considerado elemento inocuo, se estima susceptible de reportar al lector nuevos marcos para la interpretación de los mensajes.

El seguimiento y examen semiótico de textos ilustrados es la técnica escogida para desentrañar la conjunción entre el enmarcado verbal y el enmarcado visual de las unidades que conforman el trabajo de campo y, a partir de su aplicación, profundizar en la intentio operis fotográfica que revelará si el tono negativo sobre la canciller registrado en diarios españoles en una investigación precedente (SuárezRomero, 2015) imbuye la intencionalidad del elemento gráfico en la construcción de su identidad mediatizada. De hecho, así lo sugiere la principal hipótesis de este artículo, que incluye un segundo supuesto asentado en el convencimiento de que los rasgos característicos del rol de Dama de Hierro - firmeza y frialdad - permean la imagen que la prensa proyecta sobre Merkel en concomitancia con otros atributos aparentemente legados por las premisas de la nueva política -empatía y deferencia-, más enfocados a reforzar la percepción de "Mutti Merkel".

\section{Diseño metodológico}

El método seleccionado para testar las hipótesis de esta propuesta es el análisis de contenido, designado en base a la valoración que hace Bardin del proceso (2002:21): "recurrir a estos instrumentos de investigación laboriosa de documentos supone situarse en las filas de quienes, de Durkheim a Bordieu, pasando por Bachelard, quieren decir no a la ilusión de transparencia de los hechos sociales, rechazando o intentando alejar los peligros de la comprensión espontánea”. Una técnica, según matiza el autor, pensada para desconfiar de las prenociones, rechazar "la simple lectura de lo real", concebir conceptos operativos y aceptar la provisionalidad de los supuestos. 
Por su parte, los sociólogos Mayntz, Holm y Hübner (1993) definen la labor analítica como una técnica que identifica y describe de manera objetiva y sistemática las propiedades lingüísticas, con la finalidad de obtener conclusiones sobre las propiedades no lingüísticas de las personas y grupos sociales. Krippendorff (1990), sin embargo, critica su caracterización en las descripciones clásicas como herramienta para indagar en la carga simbólica ya que, para él, toda buena definición debería evitar dos connotaciones equívocas: que los mensajes tienen un significado unívoco que necesita desplegarse, y que impera la coincidencia entre los usuarios sobre esos significados.

Todo lo que no está incluido dentro de la agenda temática que configuran los medios parece carecer de interés informativo y, en consecuencia, no existe. De ahí la importancia de acometer estudios como el que ocupa estas páginas, pues la opinión pública sobre Merkel se forja en un pseudo-entorno construido por los mass media que, según Walter Lippmann, presentan las parcialidades a modo de totalidad. "De los acontecimientos públicos más trascendentales sólo vemos en el mejor de los casos una fase y un aspecto, igual que sus eminentes protagonistas, que desde dentro se encargan de redactar tratados, elaborar leyes y dictar órdenes" (Lippmann, 2003:81). Asimismo, prima recordar que hoy los ciudadanos viven inmersos en una sociedad plenamente visual, con una percepción constante de imágenes aceptadas como reales cuando proceden de determinados agentes o escenarios mediáticos (Martínez y Muñoz, 2015), y que influyen en la formación de impresiones, orientan opiniones y justifican la necesidad de emprender nuevas investigaciones.

En el caso que nos atañe, y a fin de acotar con la mayor exactitud posible la representación de la canciller alemana que la prensa española impulsa mediante la fotografía, se han seleccionado los cinco periódicos impresos de información general que, según el Estudio General de Medios (EGM) para el último año móvil disponible (febrero a noviembre de 2015), cuentan con más lectores al día: El País, El Mundo, La Vanguardia, La Voz de Galicia y El Periódico, en este orden.

Respecto a la delimitación de las fechas constitutivas de examen, se ha seguido el método de la semana construida (Riffe et al., 1996; Teramo, 2006) para obtener una muestra aleatoria representativa de un rango amplio y ofrecer una compilación libre de las distorsiones que produce la discriminación de un periodo informativo más reducido y dependiente de la actualidad del momento. Sobre esta línea de actuación se ha seleccionado el lunes de la primera semana de 2015, el martes de la segunda, y así sucesivamente hasta cubrir el periodo completo del año:

$-5,13,21$ y 29 de enero

$-6,14$ y 22 de febrero

$-2,10,18$ y 26 de marzo

$-3,11,19$ y 27 de abril

$-5,13,21$ y 29 de mayo

$-6,14,22$ y 30 de junio

$-8,16$ y 24 de julio

$-1,9,17$ y 25 de agosto

$-2,10,18$ y 26 de septiembre

$-4,12,20$ y 28 de octubre

$-5,13,21$ y 29 de noviembre

$-7,15,23$ y 31 de diciembre 
En total, la exploración durante 46 días de los diarios arriba mencionados ha derivado en la revisión de 230 ejemplares impreso completos y en la ulterior recopilación de todas las piezas en las que aparecía Angela Merkel. Posteriormente, se ha realizado un segundo y definitivo filtrado con el cual, tras agrupar únicamente las fotografías en las que figuraba la lideresa y excluir otros elementos gráficos como las viñetas humorísticas, se ha definido el corpus final de la propuesta, integrado por 77 unidades distribuidas del siguiente modo: 13, El País; 13, El Mundo; 24, La Vanguardia; 16, La Voz de Galicia, y 11, El Periódico.

En la fase de descomposición del material en unidades de análisis se ha procedido a la clasificación del contenido en base a las categorías recogidas en la plantilla de codificación. Ésta, además de ser oportunamente testada, está complementada con un libro de códigos detallado para la unificación de criterios de los codificadores. Las variables que la conforman se han diseñado atendiendo al seguimiento de las cualidades deseables para esta técnica: homogeneidad entre los diversos apartados, exclusión mutua de los ítems, pertinencia, objetividad en la realización, fidelidad al texto y productividad de los resultados (Bardin, 2002).

Como puede observarse en la tabla 1, la ficha delineada consta de cuatro apartados:

a) Datos de identificación básicos, donde se señalan características formales que incluyen el nombre del periódico al que pertenece cada fotografía, el género de la información a la que acompaña (informativo, opinativo o fotonoticia), la autoría y el tipo de elemento gráfico.

b) Localización, que permite matizar las coordenadas situacionales en las que se inserta la imagen tanto a nivel de sección (tipificando las ocho más comunes) como de página. En este contexto, atender a la colocación en página par o impar del contenido conduce a averiguar la relevancia que se concede a éste, teniendo en cuenta el impacto que conlleva la ubicación en impares.

c) Características de las fotografías, la sección más extensa de la plantilla, puesto que recoge todo lo relativo a la descripción del material visual. Se contempla el tamaño de cada instantánea seleccionando cuatro medidas generales que abarcan hasta la opción de página completa, y con idéntico interés se atiende al lugar en el que Merkel es representada, listando las situaciones o marcos en los que se circunscribe con mayor frecuencia la acción de los políticos (una reunión, un acto de campaña, una rueda de prensa y, en ciertas ocasiones, escenarios informales). Igualmente, se hace constar tanto la actualidad de la foto como el protagonismo atribuido a la canciller en la toma del retrato. Si está sola, no hay duda de que el peso de la imagen recae sobre ella, pero en caso contrario, pueden darse distintos supuestos de acompañamiento contemplados en categorías detalladas: la gobernante al lado de otros políticos, con distintos colectivos y ciudadanos o con una presencia pasiva como la que entraña el uso de su rostro en carteles, pancartas e incluso caretas a modo de sátira. Finalmente, este extenso punto se completa con variables referidas a la angulación, al tipo de plano y a otros elementos gráficos que pueden coexistir en el mismo espacio con la unidad de análisis. 
Tabla 1. Ficha de análisis para el estudio de la fotografía de Angela Merkel durante el año 2015 en El País, El Mundo, La Vanguardia, La Voz de Galicia y El Periódico. Elaboración propia.

\begin{tabular}{|c|c|}
\hline 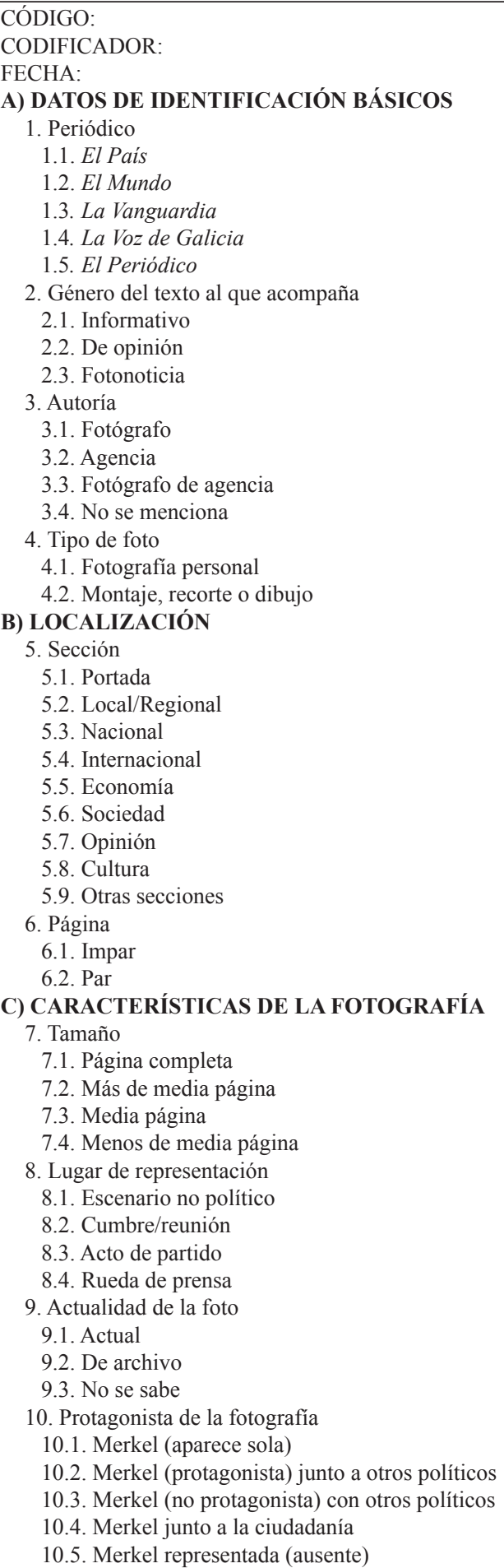 & 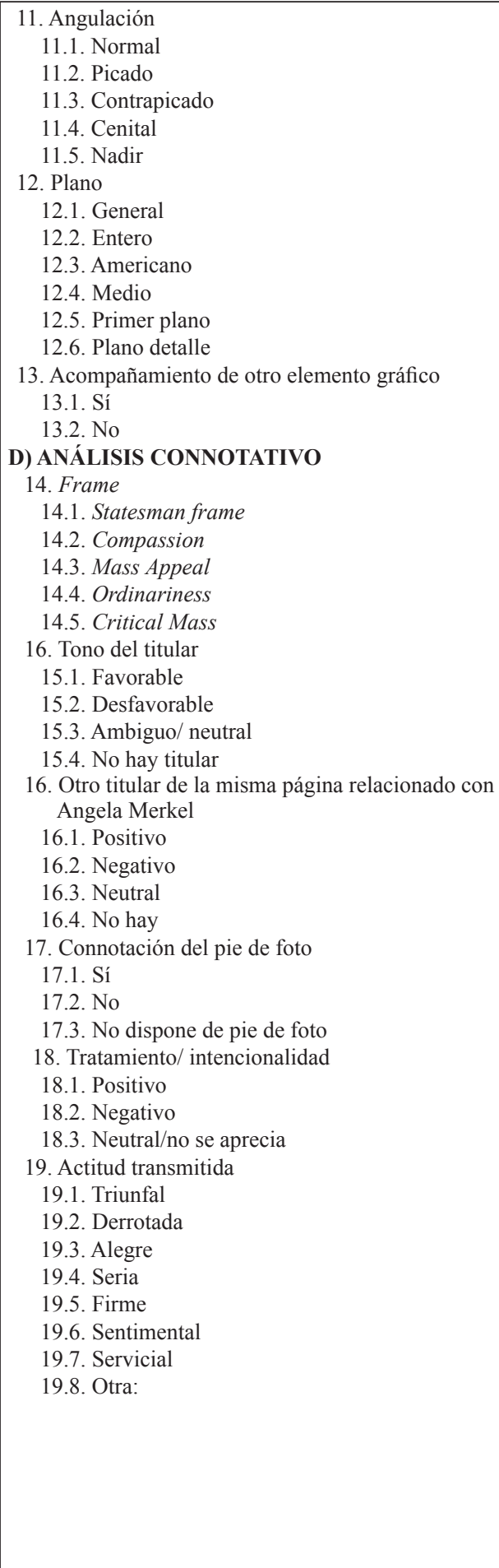 \\
\hline
\end{tabular}


d) Análisis connotativo, con el que, como su propio nombre indica, se posibilita el descubrimiento de connotaciones en las imágenes mediante la inclusión de categorías valorativas. Concretamente, la primera de ellas hace referencia al encuadre o frame, para lo cual se adoptan cinco variables inspiradas en la propuesta que Goodnow realizó en 2013 bajo el título de "Candidato ideal y popular", a fin de dividir las instantáneas de su estudio en dos bloques: las que representan al candidato político excelente y las que representan al populista. A su vez, esta estructura ofrece una doble bifurcación. Por un lado, el modelo ideal comprende aquello que ejemplifica la encarnación de las emociones y el arte de gobernar (compassion y statesmanship), mientras que el popular se vincula a la atracción de las masas y a la representación de una cotidianidad que favorece la empatía entre ciudadano y gobernante (mass appeal y ordinariness) (Quevedo et al., 2016). Así, las variables resultantes son las de statesman frame, en las que se representa a Angela Merkel como poderosa dirigente; compassion, cuando la fotografía evoca emotividad; mass appeal, en los episodios en que la lideresa aparece rodeada por personas que la apoyan; ordinariness, si destaca la faceta humana de la canciller por encima de la gubernamental y critical mass, donde los recursos visuales se dirigen a plasmar la crítica o el rechazo.

Además del encuadre, en esta cuarta sección analítica otros ítems facilitan el acercamiento a la simbología de la ilustración como elementos que la rodean de forma cercana. Es el caso del titular del texto — si lo hay — bajo el cual se inserta la instantánea, y que puede impregnar de un tono favorable, desfavorable, ambiguo o neutral la imagen de la política en función de la frase redactada. En esta línea de pensamiento, se observa si en la misma página hay otro título relacionado con Merkel $\mathrm{y}$, ante respuesta afirmativa, a qué escala valorativa responde. Como consecuencia, la categorización permite concluir qué clase de orientación del lector se efectúa mediante la extrapolación que éste hace en el proceso habitual de lectura, sin olvidar que aunque el titular en cuestión no aporte un significado añadido al retrato, en el mismo espacio puede haber otro que sí imprima un particular efecto persuasivo.

De igual manera, la tarea analítica exige estudiar cada fotografía y pie de foto, al objeto de determinar si la intencionalidad es positiva, negativa o neutra. El estudio culmina con la ponderación de la actitud que la gobernante alemana transmite en los retratos, recogiendo entre las posibles variables las formas que se presuponen más comunes en el área temática tratada: triunfal, derrotada, alegre, seria (fría), firme (decidida o inflexible), servicial y sentimental.

Para finalizar, una vez aplicada la categorización completa a las unidades constitutivas de la muestra, compete exponer los resultados desde la perspectiva del framing (Entman, 1993) para dilucidar el valor comunicativo de las imágenes. Y es que, como señalan Muñiz, Igartua, y Otero (2006: 107-108), la fotografía periodística no sólo desempeña un papel sustancial dentro de los contenidos noticiosos, sino que ejerce sobre el público una influencia de tipo cognitivo y afectivo que justifica, en buena parte de las ocasiones, la importancia de prestar mayor atención a los encuadres visuales.

\section{Resultados}

Los datos de identificación básicos de las fotografías proporcionan en este epígrafe un sustancial acercamiento a las características del corpus analizado. Concretamen- 
te, cabe explicitar en primer término que, de los cinco periódicos recopilados, $L a$ Vanguardia es el que más instantáneas de la canciller alemana publica (24), seguido por La Voz de Galicia (16), El País (13), El Mundo (13) y, por último, El Periódico (11). Como consecuencia se observa que los diarios nacionales, en contra de lo que cabría esperar, no condensan ni la mitad del total de la muestra. Son los regionales los más prolíficos en el uso de imágenes de Angela Merkel, insertadas en el 87\% de los casos en textos informativos frente al menor porcentaje que acumulan los artículos de opinión y fotonoticias, con mínima presencia en las publicaciones.

El examen del tipo de fotografía empleada también ha arrojado interesantes revelaciones, pues tan solo diez unidades enlazan con dibujos, caricaturas, imágenes de archivo y manipulaciones o montajes. La mayoría de estos corresponden a pancartas de manifestaciones diseñadas con fines ridiculizantes o de protesta. Sin embargo, también se han encontrado grafitis y portadas de periódicos internacionales que apuestan por el rostro de la lideresa para ilustrar su primera página. Sea como sea, las instantáneas captadas en el mismo lugar, momento y contexto que marca la actualidad informativa han impregnado la práctica totalidad del trabajo de campo $(87,01 \%)$, convirtiendo éste en un sucinto reflejo de la cambiante agenda mediática.

Otro aspecto que ha llamado poderosamente la atención durante la aplicación de la metodología ha sido la facilidad para encontrar en los distintos diarios idénticos elementos visuales. La razón de la repetición se encuentra en la autoría, y es que un $59,74 \%$ de las unidades analizadas se acompañan del apellido de fotógrafos de agencias que, como es habitual, venden a sus clientes productos sin exclusividad al margen de que grupos editoriales de contraria orientación ideológica coincidan con su competencia en la decisión de llevarlos a imprenta. A este porcentaje le sigue el de las firmas de agencias de noticias (19,48\%), sobre todo provenientes de FrancePress, Reuters y EFE, que a menudo obvian la identidad de sus empleados - autores de las imágenes - para publicitar el nombre de la propia empresa y aprovechar que los diarios nacionales no acostumbran a contratar a reporteros gráficos que en cada país cubran, con dedicación única para el medio, los asuntos más destacados de la jornada.

La prueba de que en España las informaciones sobre Merkel suelen vincularse al apartado de prensa "Internacional" la ofrece la variable relativa a la sección, pues la marcación preponderante es la concerniente a los asuntos políticos en el exterior $(42,86 \%)$. Consecuentemente, y a la vista de que una de las ocho opciones definidas para la categorización casi copa en solitario la mitad del corpus, se entiende lógico que el resto de posibilidades goce de una representación más modesta. Por orden decreciente, ocupan el segundo puesto las portadas, que concentran el 13\% de las imágenes de la canciller; "Economía", el 11,69\%; "Nacional", 7,79\%; "Sociedad", 3,9\%; "Opinión", 2,6\%, y, finalmente, la categoría general "Otras secciones", con algo más del $18 \%$ al aunar contenidos diversos y referentes a secciones temporales creadas con motivo de acontecimientos tan concretos como las elecciones federales de Alemania.

En cuanto a la segunda coordenada de localización, el espacio en el que se inserta la fotografía, puede decirse que prácticamente están igualadas las páginas pares (48\%) y las impares (52\%), por lo que resultaría engañoso efectuar una atribución de importancia al tema que se trata en base a la colocación considerada de mayor impacto. 
Una vez completadas las exigencias de información sobre aspectos situacionales, la naturaleza intrínseca de las instantáneas contribuye a despejar la que quizá sea la pregunta más importante del estudio: si tuviéramos que seleccionar un retrato representativo del perfil visual de Merkel en la prensa española, ¿cuál escogeríamos? De acuerdo al análisis acometido, debería ser una imagen actual, corresponder a un plano medio, ocupar menos de media página, presentar una angulación normal y ofrecer una visión donde la canciller no sólo fuera inmortalizada en el transcurso de una reunión, sino que además lo hiciera rodeada de otros políticos con los que compartir protagonismo en lugar de acapararlo. No obstante, tan ilustrativa propuesta no reflejaría las particularidades de todas las piezas examinadas, y entre ellas se incluyen casos lo suficientemente distintivos como para considerar que su impacto o efecto en la conformación de opiniones del público es mayor que el de otros elementos de la muestra.

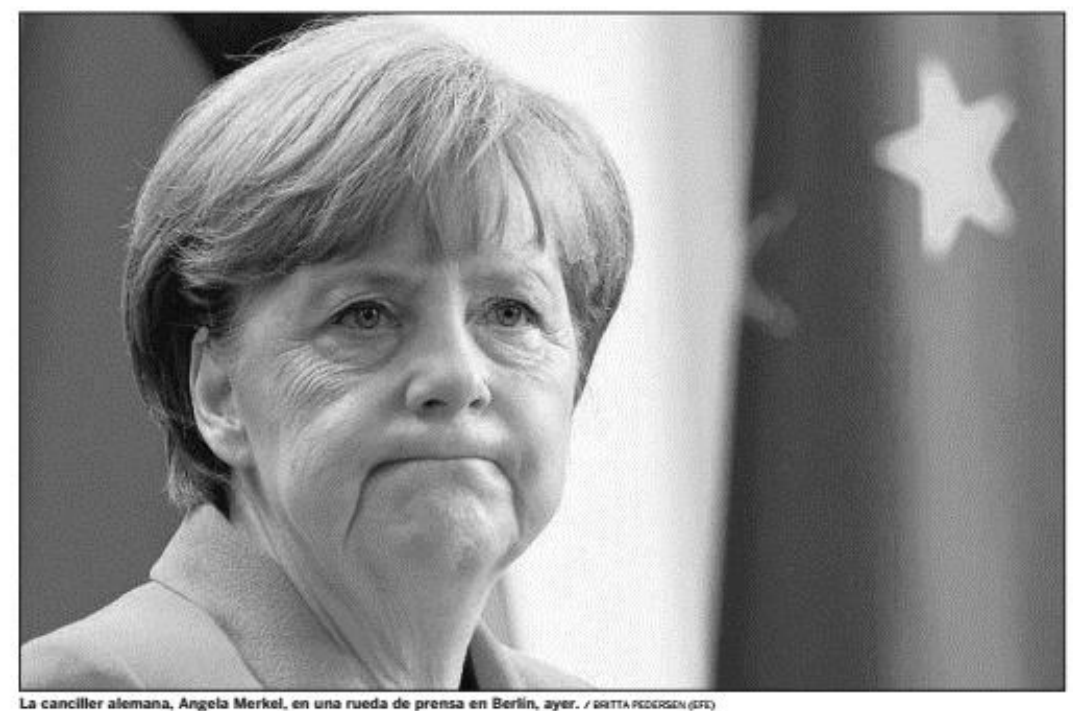

Imagen 1. Fotografía publicada en el diario El País el martes 30 de junio de 2015 (p.3). Fuente: El País.

Con la intención de no perder de vista los detalles soterrados por la media, parece conveniente comentar cada una de las variables de forma independiente, comenzando por el tamaño.

Sin duda, el espacio en los periódicos es un bien muy codiciado, y esta afirmación se multiplica exponencialmente si nos referimos a las versiones impresas. En este sentido, no es de extrañar que las dimensiones de la mayoría de fotografías concuerden con la categoría más pequeña en la escala de cuantificación, es decir, menos de media página $(76,62 \%)$, seguida por las de media página $(18,18 \%)$ y más de media $(5,06 \%)$. Así, se desprende que ningún retrato se erige tan destacado como para gozar del raro privilegio de la página completa.

Respecto a la escena, en el $73 \%$ del corpus se representa a la canciller en marcos típicamente asociados a la acción gubernamental, donde destacan las cumbres o reu- 
niones $(48,2 \%)$, las ruedas de prensa $(16,8 \%)$ y los actos organizados por el partido - la Unión Demócrata Cristina- (8\%). Las instantáneas restantes, que suponen el $27 \%$ de la totalidad, tienen como contexto espacial un escenario aparentemente no político, aunque habitualmente evocador del entorno de poder. A esta segunda categoría, por ejemplo, pertenecen las imágenes de Merkel participando en un espontáneo retrato colectivo junto a un grupo de ciudadanos (La Vanguardia, 11 de abril de 2015, p.4 y La Voz de Galicia, 4 de octubre de 2015, p.27), así como una foto de su juventud en la que posa de manera informal junto a su marido, Joachim Sauer ( $L a$ Vanguardia, 11 de abril de 2015, p.5). Impera matizar, no obstante, que el porcentaje de elementos ilustrativos de la faceta más personal de la lideresa o de su vida privada es ínfimo, prácticamente residual y siempre vinculado al limitado uso de las fotografías de archivo (el 32,47\% del total de la muestra).

En lo que a aspectos más técnicos se refiere, las angulaciones connotadas son relevantes, aunque no tanto a nivel cuantitativo como cualitativo, es decir, en la forma simbólica. Como se ha mencionado anteriormente, la angulación que prevalece es la normal (67,53\%), pero hay 25 picados y contrapicados que resultan especialmente relevantes por la sensación que con ellos se busca crear. No en vano, a través de la posición de altura que ocupa la cámara para enfocar al personaje, los picados $(11,69 \%)$ resaltan el peso de los problemas que acechan a una Merkel hundida ante situaciones como la crisis griega o la de los refugiados (El Mundo, 29 de mayo de 2015 , p.32), mientras los contrapicados (20,78\%) captan desde abajo a la gobernante para evocar su grado de poder y darle una apariencia engrandecida (El Periódico, 25 de agosto de 2015, p.4).

También el uso de los planos intermedios, tanto del medio $(38,96 \%)$ como del americano $(31,17 \%)$ es notorio, frente al de los generales y enteros registrados en menos de una decena de fotos. Igualmente, destacan los trece primeros planos que integran la muestra dotándola de la expresividad que caracteriza a este tipo de encuadres, y que a propósito de la canciller alemana reflejan el empeño de los medios en evidenciar el cansancio en su rostro y las arrugas como símbolo del agotamiento que causan el ejercicio y la responsabilidad del cargo (El Pais, 8 de julio de 2015, p.4; La Vanguardia, 22 de febrero de 2015).

En cuanto a los sujetos que componen la imagen, la lideresa aparece sola en el $18 \%$ de las ocasiones, con ciudadanos en el $13 \%$ y con otros políticos en el resto. De este modo, lo que prima es diferenciar en quién recae la significación de la toma. El trabajo de campo, empero, revela que lo más común es que los retratados compartan el papel principal (46\%) y no que sobresalga Angela Merkel (12\%), quien en un $11 \%$ de las ocasiones se convierte en involuntaria protagonista de las instantáneas al formar parte de ellas en montajes y parodias como las que la muestran con uniforme nazi en pancartas de protesta (El Mundo, 20 de octubre de 2015, p.18), o con un velo islámico (El País, 13 de enero de 2015, p.1).

Para concluir, la última parte de la labor interpretativa permite hablar del análisis connotativo propuesto en la parte final de la plantilla de codificación, donde destaca la variable "frame" para abordar el enfoque con el que la prensa española retrata a la canciller de Alemania. En este sentido, de acuerdo con lo especificado en el epígrafe metodológico, se contemplan cinco marcos correspondientes a las diferentes intencionalidades de la cobertura gráfica. Entre ellos se comprueba como el más extendido el de "Statesman frame", que ofrece una visión de la gobernante en su faceta más dura y profesional, como poderosa dirigente que atiende los asuntos que 
le competen en los más estrictos y fríos términos políticos $(63,64 \%)$. A continuación se sitúa la categoría de "Ordinariness" (16,88\%), "Critical Mass" (12,99\%), "Mass Appeal" (5,19\%) y, finalmente, "Compassion" (1,30\%). La escasa representación de las facetas más humanas y, en especial, de las muestras de empatía o flexibilidad de la dirigente en el ejercicio de su cargo, generan una dicotomía de extremos que apunta a la verificación de la principal hipótesis de esta investigación.

Junto a esa interpretación de los marcos dominantes, otras variables arrojan luz sobre el tratamiento de Merkel y permiten esbozar el siguiente gráfico:

Gráfico 1. Análisis connotativo de las imágenes de Angela Merkel publicadas durante 2015 en los periódicos objeto de estudio. Elaboración propia.

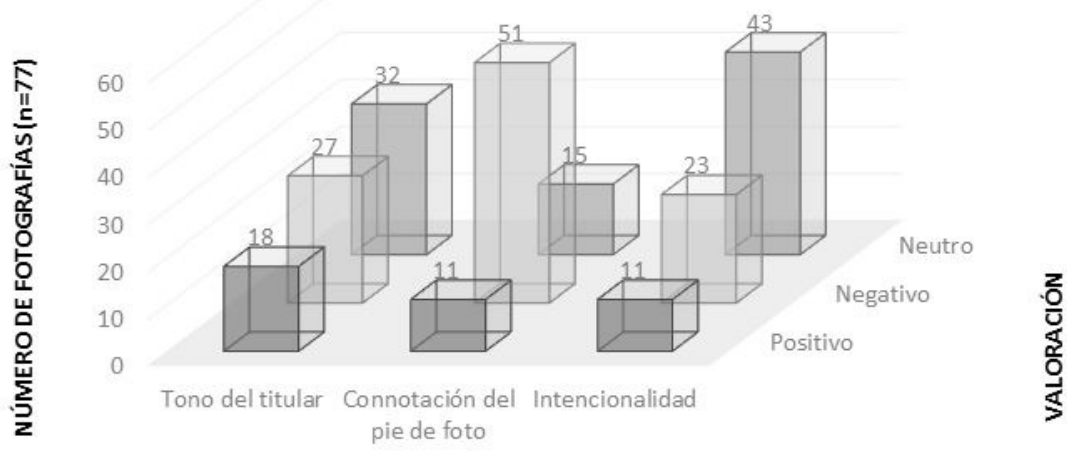

VARIABLES DE LA FICHA DE ANÁLISIS

De acuerdo a lo que puede apreciarse, el tono del titular de los textos que ilustran las fotografías es mayormente neutral $(41,56 \%)$ o desfavorable $(35,06 \%)$, y se manifiesta en frases como "La ley del silencio de Angela Merkel" en una noticia que critica su pasividad ante los casos de espionaje estadounidense (El Mundo, 5 de mayo de 2015, p.24), o "El paso atrás de Merkel" en referencia al cambio en la política migratoria con los refugiados (El Mundo, 15 de diciembre de 2015, p.24). Este segundo ejemplo es especialmente llamativo, pues la imagen que lo acompaña muestra a la política alemana intentando que se mantenga en pie un gigantesco lobo de peluche que le han regalado en un congreso de su partido, justo encima de un destacado en negrita que aborda la trágica situación de las mujeres y niños sirios.

Por otro lado, la segunda fila de columnas muestra en el gráfico la connotación de los pies de foto. Y a pesar de que casi el $20 \%$ de las instantáneas no dispone de él, en los episodios afirmativos suele limitarse a la descripción de lo que aparece en el recurso visual y a citar su autoría (66\%). No ocurre igual, sin embargo, cuando nos ajustamos al análisis de la fotografía en sí misma, pues aunque hay 43 piezas en las que no se aprecia una intencionalidad clara (están agrupadas, por tanto, en la columna "neutral"), en un $29,87 \%$ del corpus se realiza un tratamiento abiertamente negativo y contrario al escaso $14,28 \%$ de retratos de una mujer sonriente, con rostro afable y desprendiendo sensaciones aparentemente positivas. Dentro de este apartado se incluiría una de las imágenes más repetidas en la tarea recopilatoria: la que 
todos los diarios impresos - a excepción de El Mundo - escogieron a propósito de una importante cumbre de jefes de Gobierno en julio de 2015, presentando en ella a la Merkel más dispuesta y amable, cafetera en mano y, según se explicitaba en los pies de foto de El País (p.1), La Vanguardia (p.1) y La Voz de Galicia (p.2), a punto de llenar la taza del primer ministro de Grecia, Alexis Tsipras.

\section{EL PAIS}
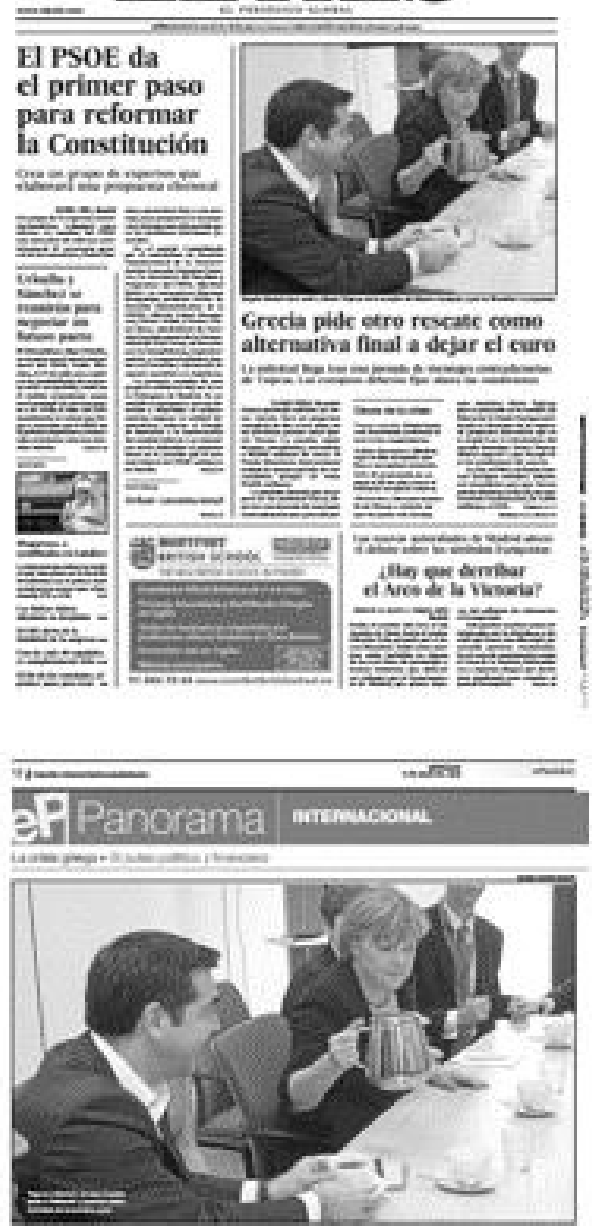

Europa le da la última oportunidad a Grecia para evitar salir del euro

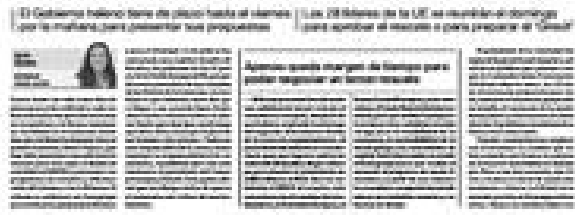

\section{LAVANGUARDIA}

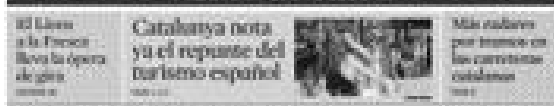

\section{Europa endurece}

sus condiciones a Grecia

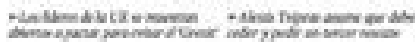

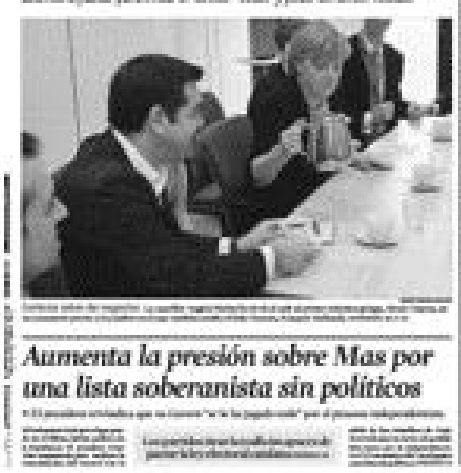

Camseoun liberalios per bovelkes endraninge

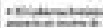

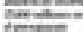

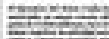
in: Laputroxis d-Cikien armbiria conodk k maknatis. thanens: Ectas au-n= Nites: coeversil: wonkes

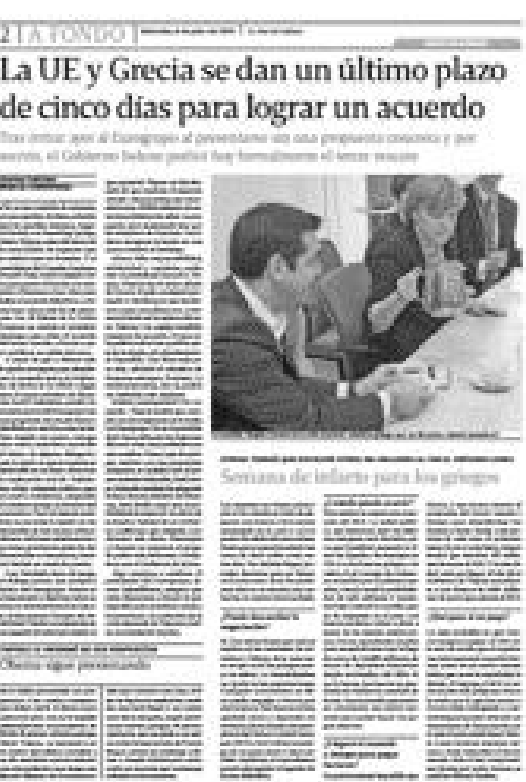

Imagen 2. La misma instantánea de Merkel ha sido publicada en cuatro de los cinco diarios examinados. Fuente: El País, La Vanguardia, El Periódico y La Voz de Galicia. 
No cabe duda de que en aquel momento la inmortalización del gesto no era casual, sino que respondía a una intención de los medios por presentarla en modo servicial, sentimental incluso, para reforzar su papel protector (la gobernante-cuidadora frente al gobernante-proveedor), e inspirar una actitud preponderante en el 18,18\% de las unidades analizadas. En todo caso, lo cierto es que en el 42,85\% de ocasiones los retratos de la canciller denotan seriedad, firmeza o inflexibilidad, frente a las expresiones de triunfo $(14,29 \%)$, derrota $(2,60 \%)$ u ostensible alegría $(16,88 \%)$.

En definitiva, y a tenor de que los últimos porcentajes referidos resultan menos significativos que los dos anteriores, se constata de nuevo la dualidad que ya se apuntó en la interpretación de los encuadres y que contrapone esos dos modelos tan bien diferenciados durante el proceso analítico: el de la afable Mutti Angela y el de la fría Dama de Hierro.

\section{Conclusiones}

El trabajo de campo en el que se fundamenta este artículo ha posibilitado la verificación de las principales hipótesis sobre la representación visual de Angela Merkel. Así, a través del basto poder de denotación de la fotografía (Barthes, 1992) se ha comprobado cómo los periódicos generalistas con mayor número de lectores apuestan por trazar la imagen del personaje severo y distante, pensativo si no inflexible, que cuando pasa a encarnar los valores tradicionalmente asignados al género femenino es identificado con el sentimentalismo o con la expresión de un supuesto instinto maternal más que con la mera empatía.

Del mismo modo, el tono negativo advertido en el titular de uno de cada tres textos concuerda con la selección de los retratos como expresiones de cierta preocupación, seriedad o rigidez, también manifiestas en la ilustración de los contenidos textuales categorizados durante la tarea analítica como neutros o menos parciales. En consecuencia, se infiere la proyección desfavorable en la construcción de la identidad mediatizada de la política alemana, apuntalada en un juego de planos contrapicados y picados cuando aparece en solitario, a fin de incidir en dos aspectos complementarios: lo que de extraordinario aún parece tener para los medios el poder de la protagonista de este estudio (contrapicados que agrandan su figura), y el presunto desgaste de la misma ante los problemas acuciantes en Europa (picados que transmiten sensación de superioridad sobre el objeto/sujeto fotografiado). Esta segunda apreciación, además, se afianza en el uso de los primeros planos para resaltar la presencia de arrugas en el rostro de la retratada y potenciar, en la mayoría de instantáneas, la advertencia de un endurecimiento y de cierta tristeza en su expresión.

Las elucidaciones expuestas, sumadas al hecho de que el enfoque imperante en la muestra sea el de statesman frame y que el contexto situacional enlace con los más comunes escenarios gubernamentales, llevan a pensar que los rasgos característicos del rol de Dama de Hierro verdaderamente permean la imagen que los diarios proyectan sobre la canciller, de acuerdo con lo previsto en la segunda hipótesis de esta propuesta. A su vez, se confirma la dispar coexistencia de esos atributos de dureza y frialdad (predominantes, insistimos, en el caso de Merkel), con otros asociados a la interpretación tradicional de la naturaleza femínea. En estas circunstancias aparecen las alusiones gráficas a Mutti Angela y se refuerza, como respuesta, la conjetura de que en cualquier episodio masculino la deferencia sería interpretada como cortesía, 
y el mencionado instinto maternal, como lógico interés por el bienestar de los ciudadanos.

Conforme a esta reflexión, sería interesante abrir una nueva línea de exploración y debate centrada en la reversibilidad de los roles políticos en función del sexo. No obstante, para abordar con consistencia — en el futuro- esas hipotéticas diferencias entre hombres y mujeres, es menester asentar ahora los cimientos de nuestra investigación con una última y definitiva aportación:

Tabla 2. Atributos para la identificación de los roles registrados en el desarrollo del trabajo de campo. Elaboración propia.

\section{TABLA DE IDENTIFICACIÓN}

\begin{tabular}{cc}
\hline Atributos de la Dama de Hierro & Atributos de Mutti Angela \\
Seria & Servicial \\
Obstinada & Atenta \\
Fría & Sentimental \\
Insensible & Vulnerable \\
Competitiva & Condescendiente \\
Déspota & Protectora \\
\hline
\end{tabular}

De esta forma, con la tabla elaborada en base al análisis connotativo de cada fotografía y en consonancia con la idea de exponer los rasgos soterrados por el pragmatismo de comprimir la categorización metodológica, concluye esta disertación enfocada a identificar en la prensa española la representación de una de las mujeres más poderosas de Europa.

¿Dama de Hierro o Mutti Angela? Para todos, sin filtros de género, hablamos de Angela Merkel.

\section{Referencias bibliográficas}

Bardin, Laurence (2002): El análisis de contenido ( $\left.3^{\mathrm{a}} \mathrm{ed}\right)$. Madrid, Akal.

Bass, Bernard M.; Avolio, Bruce J. and Atwater, Leanne (1996): "The Transformational and Transactional Leadership of Men and Women". Applied Psychology: An International Review, $1, \mathrm{n}^{\circ}$ 45, 5-34.

Burrel, Barbara C. (2004): Women and Political Participation: A reference handbook. Santa Barbara, ABC-CLIO.

Cuadrado, Isabel (2003): “Emplean hombres y mujeres diferentes estilos de liderazgo? Análisis de la influencia de los estilos de liderazgo en el acceso a los puestos de dirección". Revista de Psicología Social, 3, nº 18, 283-307.

Delgado, Santiago (2004): “Sobre el concepto y estudio del liderazgo político. Una propuesta de síntesis". Psicología Política, 29, 7-29.

Domínguez, Juan (1988): Representación de la mujer en las revistas femeninas. (Tesis doctoral). Madrid, Universidad Complutense de Madrid. 
Eagly, Alice \& Johannesen-Schmidt, Mary C. (2001): "The leadership styles of women and men”. Journal of Social Issues, 4, no 57, 781-797.

Entman, Robert (1993): "Framing: Toward a clarification of a fractured paradigm". Journal of Communication, 43, $\mathrm{n}^{\mathrm{o}} 3,51-58$

Fagoaga, Concha y Secanella, Petra María (1984): Umbral de presencia de las mujeres en la prensa española. Madrid, Instituto de la Mujer.

Falk, Erika (2008): Women for President: Media bias in eight campaigns. Chicago, University of Illinois Press.

Fernández, Nuria (2010): “Framing Hillary Clinton en la Prensa Española: ¿Candidata o Mujer?" Observatorio Journal, 3, no 4, 209-228.

Fine, Cordelia (2011): Cuestión de sexos. Barcelona, Roca

Fraser, Nancy (1997): Iustitia Interrupta. Reflexiones críticas desde la posición "postsocialista". Bogotá, Siglo del Hombre Editores.

Gallego, Juana (2013): De reinas a ciudadanas: medios de comunicación, ¿motor o rémora para la igualdad?. Barcelona, Icaria.

García-Retamero, Rocío y López-Zafra, Esther (2006): “Congruencia del rol de género y liderazgo: el papel de las atribuciones causales sobre el éxito y el fracaso". Revista Latinoamericana de Psicología, 2, no 38, 245-257.

Goodnow, Trischa (2013): "Facing Off: A Comparative Analysis of Obama and Romney Facebook Timeline Photos". American Behavioral Scientist, 57, n 11, 1584-1595.

Holmes, J. (2006): Gendered Talk at Work. Oxford, Blackwell.

Huddy, Leonie \& Terkildsen, Nayda (1993): “Gender Stereotypes and the Perception of Male and Female Candidates". American Journal of Political Science, 11, n 37, 119147.

Kanter, Rosabeth (1977): Men and Women of the Corporation. New York, Basic Books.

Krippendorff, Klaus (1990): Metodología de análisis de contenido: teoría y práctica. Barcelona, Paidós.

Lippmann, Walter (2003): La opinión pública. Madrid, Cuadernos de Langre.

López Aranguren, José Luis (1997): "El Ortega de 1914”, en López de la Vieja, María Teresa (Coord.): Política y Sociedad en José Ortega y Gasset. En torno a "Vieja y nueva politica”. Barcelona, Anthropos Editorial.

López-Hermida, Alberto Pedro (2011): "Mujer y política desde la triangulación metodológica". Revista Chilena de Comunicación, 2, 63-79.

Norris, Pippa (1997): Women, Media and Politics. New York, Oxford University Prss.

Martínez-Oña, María del Mar y Muñoz-Muñoz, Ana María (2015): "Iconografía, estereotipos y manipulación fotográfica de la belleza femenina". Estudios sobre el Mensaje Periodístico, 21 (1), 369384.

Mayntz, Renate; Holm, Kurt; y Hübner, Peter (1993): Introducción a los métodos de la sociología empírica. Madrid, Alianza.

Muñiz, Carlos; Igartua, Juan José; y Otero, José Antonio (2006): “Imágenes de la inmigración a través de la fotografía de prensa. Un análisis de contenido". Comunicación y Sociedad, 19 (1), 103-128.

Pericot, Jordi (2002): Mostrar para decir: la imagen en contexto. Barcelona, Aldea Global.

Perinat, Adolfo y Marrades, Isabel (1980): Mujer, prensa y sociedad en España (18001936). Madrid, Centro de Investigaciones Sociológicas.

Priola, Cinzia \& Brannan, Matthew (2009): "Between a Rock and a Hard Place": Exploring Women's Experiences of Participation and Progress in Managerial Careers", Equal Opportunities International, 28, 378-397. 
Quevedo, Raquel; Portalés-Oliva, Marta; y Berrocal, Salomé (2016): “El uso de la imagen en Twitter durante la campaña electoral municipal de 2015 en España”. Revista Latina de Comunicación Social, 71, 85-107.

Ramos, María Amparo (2005): Mujeres y liderazgo: una nueva forma de dirigir. Valencia, Universidad de Valencia.

Rosener, Judy B. (1990): "Ways women lead". Harvard Business Review, 68, 119-125.

Ross, Karen (2013): “A Nice Bit of Skirt and the Talking Head: Sex, politics and news”, in Carter, Cynthia; Steiner, Linda; and McLaughkin, Lisa: The Routledge Companion to Media and Gender. London, Routledge, pp. 290-299.

Riffe, Daniel; Aust, Charles F.; and Lacy, Stephen R. (1993): “The Effectiveness of Random, Consecutive Day and Constructed Week Sampling in Newspaper Content Analysis", JMC Quarterly, 70, 133-139.

Sapiro, Virginia (1981): "If US. Senator Baker were a woman: An experimental study of candidate images". Political Psychology, 3, 61-83.

Suárez-Romero, Miriam (2015): "La nueva Dama de Hierro de Europa: la creación de la imagen de Angela Merkel en la prensa española (estudio de caso de El Mundo)". Ámbitos: Revista internacional de comunicación, 27, 21-30.

Teramo, María Teresa (2006): “Calidad de la información periodística en Argentina. Estudio de diarios y noticieros". Palabra Clave, 9 (1). 57-84.

Trent, Judith S. \& Friedenberg, Robert V. (1995): Political Campaign Communication: Principles and Practices. Westport, Preager.

Raquel Quevedo Redondo es licenciada en Periodismo y Máster en Investigación de la Comunicación como Agente Histórico-Social, Quevedo trabaja en la Universidad de Valladolid con un contrato de Formación del Profesorado Universitario, además de ser miembro del proyecto titulado 'El infoentretenimiento político en televisión e Internet. Formatos, audiencias y consecuencias en la comunicación política española' (INFOPOLTNET), financiado por el Ministerio de Educación, Cultura y Deporte. Asimismo, desarrolla actividades científicas en varios proyectos de innovación docente y está integrada en el grupo de investigación 'NUTECO', reconocido por la Junta de Castilla y León para analizar nuevas tendencias en comunicación.

Miriam Suárez Romero es licenciada en Periodismo y Máster en Comunicación Institucional y Política. Miembro del grupo de investigación DEMOC-MEDIA (Medios, políticas de comunicación y democracia en la Unión Europea), reconocido oficialmente en el Sistema de Información Científica de Andalucía (SEJ-528) y adscrito al Departamento de Periodismo II de la Universidad de Sevilla, donde realiza su tesis doctoral. Actualmente ejerce como periodista becada en el Departamento de Medios de Comunicación del Senado de España. 